\title{
Using nasogastric suction but no cricoid pressure in rapid sequence induction of general anaesthesia: Outcome in a series of 224 cases of acute abdomen
}

\author{
Muhammad Ajmal* \\ ID Medical locum agency, Milton Keynes, UK
}

\begin{abstract}
Background: Classic rapid sequence induction of general anaesthesia involves cricoid pressure. We, however, use an alternative because classical rapid sequence induction experience with hypoxaemia due to possible impedance of endotracheal intubation. A prospective observational study was performed to assess the safety and efficacy of the alternative induction technique. The objective was to determine the incidence of regurgitation of gastric contents when using this technique.

Methods: During an 8-year period, general anaesthesia in patients suffering from acute abdomen was induced by placing them in a $15^{\circ}$ reverse Trendelenberg position and using nasogastric suction in the peri-induction period. Peri-induction period was defined as the period from patient's arrival in the operating room until immediately before starting the induction. Cricoid pressure was not applied. Their intra-abdominal pressure was also measured before general anaesthesia was induced. The incidence of regurgitation at induction was the end-point measure.
\end{abstract}

Results: In 224 consecutive patients with mean intra-abdominal pressure at least two times higher than normal (mean pressure $23,11.5$ and 9 mmHg in adults, children \& neonates respectively), no clinically identifiable incidence of regurgitation was noted (0/224 or $0 \%)$.

Conclusion: Rapid sequence induction of general anaesthesia can be safely and successfully performed in patients suffering from acute abdomen using nasogastric suction and omitting cricoid pressure. The findings of this study justify the need to perform larger trials to further validate this technique.

\section{Introduction}

Cricoid pressure is essential manoeuvre in classic rapid sequence induction (RSI) of general anaesthesia (GA) in patients at high risk for regurgitation and aspiration of their gastric contents [1]. However, the benefits of cricoid pressure during a RSI are still under debate $[2,3]$. The classic RSI technique of GA lacks supporting evidence and impedes smooth tracheal intubation [4]. This technique presents specific difficulties in children suffering from acute abdomen by predisposing them to episodes of hypoxaemia. Even mild episodes of hypoxaemia carry long- term adverse consequences in small children [5]. A recent review by Holmes et al. and a retrospective study by Sakai et al. reported incidences of $1 / 2000$ and $1 / 7000$, respectively, for perioperative pulmonary aspiration (PPA); however, they did not account for the population risk stratification level [6-8].

Due to its drawbacks as well as its failure to reduce the incidence of PPA, we deviated from the classic RSI technique of GA and relied on an alternate method for induction of GA in high-risk cases. In the alternate technique, cricoid pressure was ignored and nasogastric suction was used instead. A prospective observational study was conducted to evaluate the safety and success of the new RSI technique. The principal objective of the study was to determine the incidence of regurgitation of gastric contents at induction of GA in patients suffering from acute abdomen due to various causes.

\section{Materials and methods}

This study was approved by an ethical committee of the Aziz Fatima Hospital, Faisalabad, Pakistan. Data were collected from the paper based anaesthesia record. The study population included consecutive patients who presented with acute abdomen and required surgery during the period from 1991 to 1999 . During this period all patients undergoing laparatomy for acute abdomen were induced using a consistent GA technique. Each patient was kept nil by mouth after admission to the hospital and was rehydrated using intravenous fluids. Each patient had a nasogastric tube in place before coming to the operating room. Before induction, the patient's intra-abdominal pressure (IAP) was assesses [9]. Each patient was placed in $15^{\circ}$ reverse- Trendelenberg position, and his/her head was stabilised on a sand bag with the neck flexed and head extended. During the peri-induction period, an assistant aspirated the nasogastric tube with a syringe; applying an aspiration after every minute. A 20, 10- and 5-ml disposable syringe was used for nasogastric tube suction in adults, children and infants and neonates respectively. The total volume of aspirate in each patient was recorded. The periinduction period was defined as the period starting from the patient's arrival in the operating room until immediately before starting the induction. Nasogstric tube was removed immeidately before induction and oropharynx of the patient was suctioned. All adult patients, except

${ }^{\star}$ Correspondence to: Muhammad Ajmal, Locum Anaesthetist, ID Medical locum agency, Milton Keynes, UK, Tel: 00447575770303; E-mail: Ajmal_c@hotmail.com

Key words: acute abdomen, rapid sequence induction of general anaesthesia, nasogastric suction, cricoid pressure

Received: October 10, 2018; Accepted: October 22, 2018; Published: October 29,2018 
Table 1. Patient characteristics

$\mathrm{n}=224$

\begin{tabular}{|c|c|}
\hline Age (range) & 2 day -90 year \\
\hline Weight (range) & $1.75-80 \mathrm{~kg}$ \\
\hline $\begin{array}{l}\text { Gender: } \\
\text { (male / female) }\end{array}$ & $128 / 96$ \\
\hline $\begin{array}{l}\text { Age group: } \\
\text { neonate / infant / children / adult }\end{array}$ & $24 / 6 / 44 / 150$ \\
\hline $\begin{array}{l}\text { Anesthesia risk: } \\
\text { ASA-I / ASA-II / ASA-III / ASA-IV }\end{array}$ & $186 / 27 / 8 / 3$ \\
\hline $\begin{array}{l}\text { Mallampati grade (adult = 150): } \\
\text { I / II / III / IV }\end{array}$ & $110 / 31 / 9 / 0$ \\
\hline $\begin{array}{l}\text { Surgical diagnosis (neonates }=24 \text { ): Hurshprung / malrotation of gut / duodenal atresia / } \\
\text { imperforate anus / } \\
\text { necrotizing enterocolitis }\end{array}$ & $\begin{array}{c}14 / 4 / \\
3 / 2 / \\
1\end{array}$ \\
\hline $\begin{array}{l}\text { Surgical diagnosis (infants }=6 \text { ): non-functioning colostomy / } \\
\text { intussusception / blunt trauma gut }\end{array}$ & $\begin{array}{c}2 \\
2 / 2\end{array}$ \\
\hline $\begin{array}{l}\text { Surgical diagnosis }(\text { children }=44) \text { : perforated appendix / typhoid perforation / tuberculosis } \\
\text { of gut / trauma gut } / \\
\text { iatrogenic uterine perforation }\end{array}$ & $\begin{array}{c}20 / 15 / \\
5 / 3 / \\
1\end{array}$ \\
\hline $\begin{array}{l}\text { Surgical diagnosis (adult }=150 \text { ): } \\
\text { typhoid perforation / perforated appendix / tuberculosis of gut / volvulus gut / fecal impaction } \\
\text { / carcinoma colon / trauma gut }\end{array}$ & $\begin{array}{l}70 / 30 / \\
29 / 12 / \\
5 / 3 / 1\end{array}$ \\
\hline
\end{tabular}

those with American Society of Anaesthesiologist (ASA)-IV-E status, were induced with sodium thiopental (4-6 mg/kg body weight) and suxamethonium (1-1.5 mg/kg body weight) after preoxygenation for 3 minutes. The ASA-IV-E adults and all infants and neonates were induced with inhaled halothane in 100\% oxygen and an injection of suxamethonium. An Ayres' T piece was used to deliver gases to neonates, infants and small children. Magill's circuit (Mapleson A) was used for adults and big children. Cricoid pressure was never applied on any of the patients. Incidence of regurgitation of gastric contents during induction of anaesthesia was the end-point measure. Occurrence of regurgitation was based on the anaesthetist's direct observation of the presence of gastric contents in the airway or endotracheal tube.

\section{Results}

Over 8 years, 224 patients with acute abdomen were admitted to the hospital and required GA for their surgery. One hundred and twenty-eight (57\%) patients were male, and 96 (43\%) were female. One hundred and fifty of these patients (67\%) were adults and $74(33 \%)$ were children. Their ages ranged from 2 days to 90 years and their weights from 1.25 to $80 \mathrm{~kg}$. No patient was morbidly obese or suffered from obstructive sleep apnoea. On the ASA physical risk scale, $186(83 \%)$ were of ASA-I-E, 27 (12\%) ASA-II-E, 8 (4\%) ASA-III-E and 3 (1\%) patients were ASA-IV-E. Other subject-related characteristics are summarised in Tables 1 for adults and children, respectively.

The mean IAP in neonates and children were 9 and $11.5 \mathrm{mmHg}$, respectively. In adults, the mean IAP was 23; with a range of 17-28 mmHg [IAP was more than two times higher than the normal range in the study population]. The mean fasting time in study population was 7 hours with a range of 4.5 to 10 hours. The mean volume of periinduction aspirate was 30,12 and $7 \mathrm{ml}$ in adults, children, and infants and neonates respectively. GA was successfully induced in all patients using the technique described in the methods section. No cases $(0 / 224)$ of gastric regurgitation were encountered.

\section{Discussion}

The results of this study indicated that the induction of GA without cricoid pressure in patients suffering from acute abdomen with high IAP was safe and effective when an appropriate alternative technique was applied. No incidence (0/224) of regurgitation at indcution of GA in this high-risk study population was encountered. A previous study showed similar results when cricoid pressure in a population that was potentially high-risk for PPA was not applied [10]. This study targeted a uniform population of high-risk patients suffering from acute abdomen with high IAP. The IAP was more than two times higher than normal in the study population [11-14]. There was no incidence of regurgitation in our study population despite the relatively high risk due to raised IAP.

This study has certain limitations. Our observations were limited to identifying clinically evident regurgitation only. The study was conducted at a single community-level facility; therefore, only a limited number of subjects were available for recruitment over the 8-year period which resulted in week nature of the data due to power limitation. The ages of our study population were quite heterogeneous whereas the incidence of regurgitation in exclusive paediatric population could be relatively high. Our primary aim was to perform preliminary observations to assess the outcome of the technique in a high-risk population.

\section{Conclusion}

We conclude that RSI of GA in patients suffering from acute abdomen can be safely performed utilising nasogastric suction in the peri-induction period without the need for cricoid pressure. Our findings should further be validated in a heterogeneous age group population.

\section{References}

1. Sellick BA (1961) Cricoid pressure to control regurgitation of stomach contents during induction of anaesthesia. Lancet 2: 404-406. [Crossref] 
2. Lerman J (2009) On cricoid pressure: "may the force be with you". Anesth Analg 109: 1363-1366. [Crossref]

3. El-Orbany M, Connolly L (2010) Review article: Rapid sequence induction and intubation: Current controversy. Anesth Analg 110: 1318-1325. [Crossref]

4. Isono S, Greif R, Mort TC (2011) Airway research: the current status and future directions. Anaesthesia 66: 3-10. [Crossref]

5. Bass JL, Corwin M, Gozal D, Moore C, Nishida H, et al. (2004) The effect of chronic or intermittent hypoxia on cognition in childhood: a review of the evidence. Pediatrics 114 : 805-816. [Crossref]

6. Sakai T, Planinsic R, Quinlan J, Handley L, Kim Tae-Yop, et al. (2006) The Incidence and Outcome of Perioperative Pulmonary Aspiration in a University Hospital: A 4-Year Retrospective Analysis. Anesth Analg 103: 941-947. [Crossref]

7. Kluger M T, Short T G (1999) Aspiration during anaesthesia: a review of 133 cases from the Australian Anaesthetic Incident Monitoring Study (AIMS). Anaesthesia 54. 19-26. [Crossref]
8. Holmes N, Martin D, Begley AM (2011) Cricoid pressure: a review of the literature. $J$ Perioper Pract 21: 234-238. [Crossref]

9. Iberti TJ, Lieber CE, Benjamin E (1989) Determination of intra-abdominal pressure using a transurethral bladder catheter: clinical validation of the technique. Anesthesiology 70: 47-50. [Crossref]

10. Ajmal M (2011) General anaesthesia for caesarean sections: are anaesthetists dealing with exaggerated fear? Eur J Anaesthesiol 28: 815-816. [Crossref]

11. Allman KG (1995) The effect of cricoid pressure application on airway patency. J Clin Anesth 7: 197-199. [Crossref]

12. Walker RW, Ravi R, Haylett K (2010) Effect of cricoid force on airway calibre in children: a bronchoscopic assessment. Br J Anaesth 104: 71-74. [Crossref]

13. Saghaei M, Masoodifar M (2001) The pressor response and airway effects of cricoid pressure during induction of general anaesthesia. Anesth Analg; 93: 787-90. [Crossref]

14. Sanchez NC, Tenofsky PL, Dort JM, Shen LY, Helmer SD, et al. (2001) What is normal intra-abdominal pressure? Am Surg 67: 243-248. [Crossref]

Copyright: $\left({ }^{2} 2018\right.$ Ajmal M. This is an open-access article distributed under the terms of the Creative Commons Attribution License, which permits unrestricted use, distribution, and reproduction in any medium, provided the original author and source are credited. 